\title{
Novel antiplatelet agents in the prevention of cardiovascular complications - focus on ticagrelor
}

REVIEW

This article was published in the following Dove Press journal:

Vascular Health and Risk Management

24 May 2010

Number of times this article has been viewed

\author{
Margaret M Marczewski' \\ Marek Postula ${ }^{1,2}$ \\ Dariusz Kosior' \\ 'Ist Chair and Department of \\ Cardiology, Central University \\ Hospital, Medical University of \\ Warsaw, Warsaw, Poland; ${ }^{2}$ Department \\ of Experimental and Clinical \\ Pharmacology, Medical University \\ of Warsaw, Warsaw, Poland
}

\begin{abstract}
Atherothrombosis, thrombus formation as a result of atherosclerotic plaque rupture, is a major modern health problem, often underlying coronary artery disease, stroke, and peripheral arterial disease. After the treatment of an acute thrombotic episode, long-term therapy is warranted as a secondary prophylaxis of such events and their complications. Because of the importance of platelets' involvement in the initiation and propagation of thrombosis, antiplatelet drugs have come to the forefront of atherothrombotic disease treatment. Dual antiplatelet therapy of aspirin plus clopidogrel - the current standard - has its benefits, but it also has its limitations with regard to its pharmacologic properties and adverse effects. For these reasons, within the last decade or so, the investigation of novel antiplatelet agents has prospered. Here, we review the main pathways through which platelets participate in acute thrombosis and the interruption of these pathways by using novel antiplatelet agents, including $\mathrm{P} 2 \mathrm{Y}_{12}$ receptor antagonists (the recently approved prasugrel, the probable next-in-line ticagrelor, and others). The need for a more individualized patient therapy is evident; although most of the aforementioned pharmaceuticals have the potential to contribute to this, their clinical utility remains to be seen.
\end{abstract}

Keywords: antiplatelet therapy, antagonist, $\mathrm{P}_{2} \mathrm{Y}_{12}$ receptor, $\mathrm{ADP}$ receptor

\section{Different classes of platelet-inhibiting drugs}

Platelets have an established role in the pathogenesis of atherosclerosis-related diseases, including coronary artery disease (CAD), acute coronary syndromes (ACSs), and stroke. Rupture of an atherosclerotic plaque promotes the activation of platelets and initiates the coagulation cascade. Activation of platelets and their subsequent aggregation, which is amplified by various pathways, lead to thrombus formation at the site of vascular injury. Tissue hypoxia and irreversible damage in conditions such as myocardial infarction (MI) and ischemic stroke are rather due to an acute thrombus formed atop a ruptured atherosclerotic plaque than due to the stenosis caused by atherosclerosis. ${ }^{1}$ Thus, antiplatelet agents have been used in acute conditions of arterial thrombosis and as part of secondary prophylaxis to prevent recurrent thromboembolic episodes.

Acetylsalicylic acid (aspirin) was the first antiplatelet agent, which irreversibly inhibits the cyclooxygenase 1 enzyme in the arachidonic acid pathway through acetylation, thereby preventing the conversion of arachidonic acid into thromboxane A2 $\left(\right.$ TXA $\left._{2}\right)$ - a potent vasoconstrictor and platelet activator. ${ }^{2}$ Despite being used as a drug for more than 100 years, aspirin continues to play a dominant role in the treatment of cardiovascular diseases (CVDs) because of its ease of use and cost-effectiveness. 
Long-term aspirin therapy brings about a 20\%-25\% odds reduction in the risks of subsequent $\mathrm{MI}$, stroke, or vascular death among intermediate- to high-risk patients with atherothrombotic disease. ${ }^{3,4}$ However, its relatively low potency [producing only a partial inhibition of platelet aggregation (IPA)], some patients' resistance to aspirin, and its gastrointestinal toxicity prompted the search for more potent, more consistent, and more specific

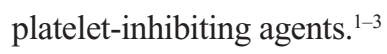

Currently, two classes of antiplatelet drugs are used alongside aspirin. Clopidogrel, a thienopyridine adenosine diphosphate (ADP) receptor antagonist, on the basis of a 12,562-patient study, CURE (Clopidogrel in Unstable angina to prevent Recurrent Events) trial in 2001, has become a standard part of dual antiplatelet therapy with aspirin, which is used for a longer term after an acute MI. ${ }^{5}$ Glycoprotein $\mathrm{IIb} / \mathrm{IIIa}$ (GP IIb/IIIa) antagonists, such as abciximab, are used in high-risk patients before percutaneous coronary intervention (PCI). ${ }^{3}$ The limitations of clopidogrel - its delayed onset of action, interpatient variability in response to clopidogrel (including some patients' outright resistance to it), and the irreversibility of its action - have encouraged the investigation of novel antiplatelet agents with satisfactory safety profiles and adequate efficacy.,6,7

The process of platelet activation and aggregation involves multiple signaling molecules and their receptors, therefore allowing for many therapeutic targets. First, platelets adhere to the subendothelial proteins (ie, von Willebrand factor and collagens) exposed at sites of vascular injury. This is followed by intracellular signaling, with platelet activation and secretion of further mediators, which amplify and sustain the initial platelet response. ${ }^{8}$ In particular, activated platelets release ADP, serotonin, and calcium via degranulation, as well as synthesize thromboxane from arachidonic acid; thrombin, another key substance, is locally generated through the coagulation cascade. ${ }^{9,10}$ Platelet activation is propagated through blood-soluble agonists acting upon their respective platelet receptors: $\mathrm{ADP}$ via $\mathrm{P} 2 \mathrm{Y}_{1}$ and $\mathrm{P} 2 \mathrm{Y}_{12}$, thrombin via protease-activated receptor 1 (PAR1) and PAR4, and thromboxane via the thromboxane/prostanoid (TP) receptor. ${ }^{11}$ The final common pathway for all these autocrine and paracrine activation signals is GP IIb/IIIa-mediated platelet aggregation. Thus, in both physiologic hemostasis and pathologic states, platelets are recruited into the mass of a platelet - fibrin thrombus. ${ }^{9-11}$

The various classes of antiplatelet drugs act synergistically through complementary yet independent mechanisms, preventing platelet aggregation and thus acute thrombus formation. Currently available drugs and those under investigation target the thromboxane-induced (ie, aspirin and terutroban), ADP-induced (such as ticlopidine, clopidogrel, and prasugrel), and thrombin-induced (eg, SCH 530348 and E5555) pathways of platelet activation and their final common pathway of GP IIb/IIIa (abciximab, eptifibatide, and tirofiban)-induced platelet aggregation. ${ }^{11-14}$ The processes of platelet adhesion, activation, and aggregation along with the targets of platelet-inhibiting drugs are shown in Figure 1.

All antiplatelet drugs, in addition to inhibiting acute arterial thrombosis, have the danger of interfering with the physiologic role of platelets in hemostasis. Thus, the range of adverse effects, particularly bleeding, is a major factor in evaluating the utility of the available and upcoming antiplatelet drugs and their combination regimens. In addition to the safety profile and drug efficacy, other factors to be taken into account when choosing from the available and developing antiplatelet drugs include the specificity to platelets, route of administration, reversibility of action, the onset of action, peak of effect, and its duration or wearing-off time (offset).

\section{Blockade of ADP receptors of subtype $P 2 Y_{12}$ - from the molecular level to the clinical utility of thienopyridines}

The key role of ADP in the processes of platelet aggregation and thrombus formation has led to the development of antiplatelet drugs targeting the $\mathrm{P} 2 \mathrm{Y}_{12}$ receptor. Activated platelets release ADP from their dense granules, which functions as a soluble positive feedback mediator that binds to the receptors $\left(\mathrm{P} 2 \mathrm{Y}_{1}\right.$ and $\mathrm{P} 2 \mathrm{Y}_{12}$ ) on the platelets' surface. Both these purinoreceptors belong to the group of G-protein-coupled receptors, with $\mathrm{P} 2 \mathrm{Y}_{1}$ being coupled to $\mathrm{G}_{\mathrm{q}}$ and $\mathrm{P} 2 \mathrm{Y}_{12}$ to $\mathrm{G}_{\mathrm{i}}$; thus, each subtype of ADP receptor has a distinct intracellular signaling pathway. ${ }^{9,10}$ Stimulation of the $P 2 Y_{1}$ receptor and its $G_{q}$ protein mobilizes intracellular calcium and triggers a change in the platelet shape and rapidly reversible aggregation. ${ }^{15}$ A signal through the $\mathrm{P} 2 \mathrm{Y}_{12}$ receptor and its $\mathrm{G}_{\mathrm{i}}$ protein results in reduced levels of cyclic adenosine monphosphate, amplification of the platelet response, stabilization of the resulting aggregates, and secretion of further mediators from the granules. ${ }^{16}$ Although the coactivation of both purinoreceptors is necessary for normal ADP-induced aggregation, $\mathrm{P}_{2} \mathrm{Y}_{12}$ is considered the major platelet ADP receptor, and because of its more restricted expression, it has become an attractive therapeutic target of antithrombotic agents. ${ }^{9,13,17}$

The thienopyridine class of antiplatelets (ticlopidine, clopidogrel, and prasugrel) selectively and irreversibly 
PLATELET

\section{A) ADHESION}

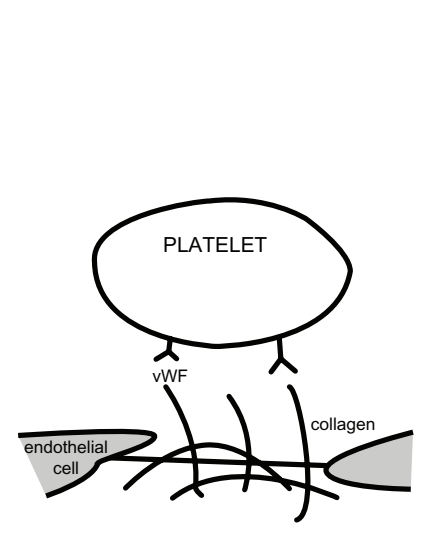

B) ACTIVATION

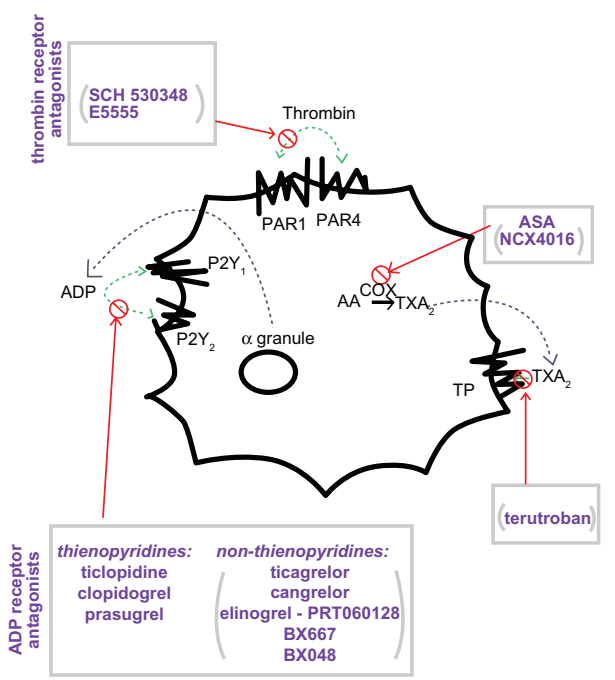

C) AGGREGATION

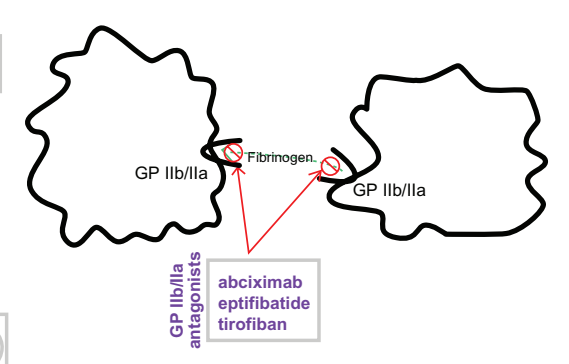

Figure I Scheme of platelet adhesion, activation, and aggregation processes - showing the key players and sites of action of antiplatelet agents. Drugs at various stages of investigation appear in parentheses.

Abbreviations: AA, arachidonic acid; ADP, adenosine diphosphate; ASA, aspirin; COX, cyclooxygenase; GP, glycoprotein; PAR, protease-activated receptor; PR, thromboxane/ prostanoid receptor; TXA 2 , thromboxane; vWF, von Willebrand Factor.

inhibits the $\mathrm{P} 2 \mathrm{Y}_{12}$ purinoreceptor throughout the lifespan of the platelet. Although currently clopidogrel is the dominant member, its modest platelet inhibition, delayed onset of action, and significant interpatient variability in response to clopidogrel (including some patients' nonresponsiveness to the drug) paved the way for more potent and stable drugs. ${ }^{18}$ Ticlopidine had been discovered before clopidogrel, but has been eclipsed because of its adverse hematologic side effects, including neutropenia and thrombotic thrombocytopenic purpura. ${ }^{3}$ The opposite is true of the third-generation thienopyridine, prasugrel - previously known as CS-747, LY-640315 - which has been approved by the United States Food and Drug Administration recently and has found a place in the latest recommendations of British and American institutions. ${ }^{19,20}$

All the orally administered thienopyridines are prodrugs, which require biotransformation into their active metabolites by fixed sets of hepatic cytochrome P450 (CYP) enzymes, in particular, the CYP3A4 isozyme. In contrast to clopidogrel's esterase inactivation and two-step CYP-dependent activation, prasugrel has a more efficient and simpler metabolism, which requires only one reaction by the liver enzymes to yield its active metabolite. ${ }^{21,22}$ This difference in the metabolism of these thienopyridines translates clinically into different patient responses and drug interactions with these antiplatelet agents. Certain common genetic variants of
CYP2C19 resulted in decreased levels of clopidogrel's active metabolite, resulting in a lower platelet inhibition and most importantly a higher rate of major adverse cardiovascular events; on the other hand, prasugrel's pharmacology and clinical efficacy were not found to be affected by CYP polymorphisms or by the concomitant use of CYP-inhibitory drugs. Other advantages of prasugrel include a faster onset of action and an approximately tenfold higher potency than clopidogrel. ${ }^{22-27}$

Prasugrel has been shown to be of particular benefit in patients with diabetes, especially those on insulin $(30 \%$ relative risk reduction [RRR] in cardiovascular death, MI, or stroke $[P<0.001]$ and $37 \% \mathrm{RRR}$, respectively). Another look at the TRITON-TIMI 38 data with respect to diabetes status showed the reduction by prasugrel of the composite of CV death, MI and stroke noted in non-diabetic subjects (n $=10,462,9.2 \%$ vs $10.6 \%, P=0.02$ ), was even more significant in those with diabetes mellitus $(\mathrm{n}=3,146,12.2 \%$ vs $17.0 \%, P<0.001)$, especially those treated with insulin (n $=776,14.3 \%$ vs $22.2 \%, P=0.009) .{ }^{14,28}$ On the other hand, its dose should be adjusted for low-weight patients $(<60 \mathrm{~kg})$, and it should be rather avoided in the elderly ( $\geq 75$ years) and in those with a history of stroke or transient ischemic attack because of an increased bleeding risk. ${ }^{29}$ Such recommendations are largely based on the results of the Phase 3 TRITON-TIMI 38 (TRial to assess Improvement 
in Therapeutic Outcomes by optimizing platelet inhibition with prasugrel - Thrombolysis In Myocardial Infarction 38) on 13,608 patients with ACS undergoing planned PCI ${ }^{30}$ It demonstrated the composite rate of death, MI, or stroke to be reduced by $19 \%$ and the rate of stent thrombosis to be halved in patients receiving prasugrel compared with those receiving clopidogrel. Although prasugrel had an increased efficacy, it also increased the risk of bleeding, especially in the aforementioned groups, including life-threatening hemorrhage and fatal bleeding. ${ }^{14,30}$

Although prasugrel is still under investigation, it has already found an official place in antiplatelet therapy through support from American and British institutions. In October 2009, the United Kingdom's National Institute for Health and Clinical Excellence recommended a limited use of prasugrel, in combination with aspirin, in three specific but sizeable subgroups of patients with ACS undergoing PCI: those undergoing immediate primary PCI for myocardial infarction with ST elevation (STEMI), those who had stent thrombosis during clopidogrel treatment, and those with diabetes mellitus. ${ }^{20}$ In November 2009, the American College of Cardiology, the American Heart Association, and the Society for Cardiovascular Angiography and Interventions jointly released guidelines for the use of prasugrel in patients with STEMI once the coronary anatomy is known and PCI is planned. ${ }^{19}$

\section{Ticagrelor - an overview of its pharmacologic and clinical profiles}

Novel nonthienopyridine platelet $\mathrm{P}_{2} \mathrm{Y}_{12}$ receptor antagonists, including ticagrelor, cangrelor, and elinogrel, are also being investigated. These are direct and reversible $\mathrm{P} 2 \mathrm{Y}_{12}$ antagonists with various formulations but with rapid onsets and short durations of action. Among these, ticagrelor has come the furthest, having undergone a Phase 3 clinical trial. ${ }^{31}$ As a prototype drug from the novel cyclopentyltriazolopyrimidine class of antiplatelets, ticagrelor (previously known as AZD6140) is chemically distinct from the thienopyridines and can reversibly inhibit the P2Y ${ }_{12}$ ADP receptor. It is highly selective and very specific for the $\mathrm{P} 2 \mathrm{Y}_{12}$ receptor, and it exhibits a greater, more consistent IPA than clopidogrel. ${ }^{32}$ Like the thienopyridines, ticagrelor is also administered orally, but because of its direct action, ie, not requiring metabolic activation, ticagrelor has a rapid onset, peaking within 2-4 hours of dosing. ${ }^{33}$ The metabolism of ticagrelor yields an active molecule (AR-C124910XX) that has similar $\mathrm{P} 2 \mathrm{Y}_{12}$-blocking activity as its parent molecule. Ticagrelor's plasma half-life is approximately 12 hours, which corresponds to twice-daily dosing. In contrast to clopidogrel and prasugrel, which should be discontinued approximately 5 days before the restoration of normal platelet-mediated hemostasis, ticagrelor's short duration of action and an offset of action in 1-2 days preclude the need for delaying surgical intervention, such as coronary artery bypass grafting (CABG). On the other hand, this potential advantage also carries the risk of increased thrombotic events if patients miss a ticagrelor dose. ${ }^{14,18,19}$ The pharmacologic properties of some currently used and investigational antiplatelet drugs are shown in Table 1.

Several Phase 2 clinical trials have been conducted using ticagrelor, the first reversibly binding oral $\mathrm{P} 2 \mathrm{Y}_{12}$ receptor antagonist (Table 2). In an initial Phase 2a parallel-group safety and efficacy trial (DISPERSE), 200 patients with atherosclerosis were randomized to receive either ticagrelor (doses of 50, 100, or $200 \mathrm{mg}$ twice daily, or $400 \mathrm{mg}$ once daily) or clopidogrel ( $75 \mathrm{mg}$ once daily) for 28 days, in addition to $75-100 \mathrm{mg}$ of aspirin per day. Measuring the IPA showed that the three higher doses of ticagrelor (ie, 100 and $200 \mathrm{mg}$ twice daily and $400 \mathrm{mg}$ once daily) provide a nearly complete inhibition of ADP-induced platelet aggregation after the initial dosing. Although investigators write that in general ticagrelor was well tolerated, there was a higher incidence of bleeding with the three higher doses, mostly of mild to moderate severity, and there were also reports of dyspnea. ${ }^{36}$

This trial was followed by the Phase $2 b$ Dose confIrmation Study assessing anti-Platelet Effects of AZD6140 vs clopidogRel in non-ST-segment Elevation acute coronary syndromes (DISPERSE-2) trial. ${ }^{37}$ In this trial, 990 patients with non-ST-segment elevation ACS were randomized to receive any one of the following dosage: ticagrelor $90 \mathrm{mg}$ twice daily, ticagrelor $180 \mathrm{mg}$ twice daily, or clopidogrel $300 \mathrm{mg}$ loading dose plus $75 \mathrm{mg}$ once daily for up to 12 weeks. This study showed no difference in major bleeding but an increase in minor bleeding at the higher dose of ticagrelor, with encouraging - although not statistically significant results on the secondary end point of MI. ${ }^{37}$ For the possible advantage of ticagrelor's reversible inhibition, there was only a numerically lower rate of bleeding (again nonsignificant) in ticagrelor-treated patients undergoing CABG between 1 and 5 days after stopping ticagrelor, which would be consistent with the recovery of platelet function. Another analysis of the DISPERSE-2 data compared the antiplatelet effects of ticagrelor with those of clopidogrel and assessed the effects of ticagrelor on clopidogrel-pretreated patients. ${ }^{39}$ It demonstrated that ticagrelor treatment resulted in further IPA in 
Table I Pharmacologic properties and adverse effects of a selection of antiplatelet agents

\begin{tabular}{|c|c|c|c|c|c|c|c|}
\hline Drug & Action & $\begin{array}{l}\text { Aggregation } \\
\text { to ADP }\end{array}$ & $\begin{array}{l}\text { Route of } \\
\text { administration }\end{array}$ & Metabolism & $\begin{array}{l}\text { Time to } \\
\text { peak effect }\end{array}$ & $\begin{array}{l}\text { Offset of } \\
\text { action }\end{array}$ & Adverse effects \\
\hline $\begin{array}{l}\text { Clopidogrel } \\
300 \mathrm{mg}\end{array}$ & IRR & $\sim 30 \%$ & Oral & $\begin{array}{l}\text { Esterase inactivation } \\
\text { and two-step hepatic } \\
\text { CYP-dependent } \\
\text { activation }\end{array}$ & $\sim 4$ hours & $\sim 5$ days & $\begin{array}{l}\text { Bleeding (major and } \\
\text { minor), interpatient } \\
\text { variability, and } \\
\text { dyspnea in } \\
\text { approximately } \\
8 \% \text { of patients }{ }^{34}\end{array}$ \\
\hline $\begin{array}{l}\text { Prasugrel } \\
60 \mathrm{mg}\end{array}$ & IRR & $75 \%-80 \%$ & Oral & $\begin{array}{l}\text { Esterase activation } \\
\text { and one-step CYP- } \\
\text { dependent activation } \\
\text { (liver or gut) }\end{array}$ & I-2 hours & $\sim 5$ days & $\begin{array}{l}\text { Bleeding (major and } \\
\text { minor) and dyspnea in } \\
\text { approximately } \\
5 \% \text { of patients }{ }^{30}\end{array}$ \\
\hline Ticagrelor & $\mathrm{R}$ & $75 \%-80 \%$ & Oral & None required & I-2 hours & I-2 days & $\begin{array}{l}\text { Bleeding, dyspnea in } \\
\text { approximately } \\
14 \% \text { of patients, } \\
\text { and ventricular pauses }{ }^{31}\end{array}$ \\
\hline $\begin{array}{l}\text { Cangrelor } \\
4 \mu \mathrm{g} / \mathrm{kg} / \mathrm{min}\end{array}$ & $\mathrm{R}$ & $>90 \%$ & Intravenous & None required & Minutes & 20 minutes & $\begin{array}{l}\text { Bleeding (minor) and } \\
\text { dyspnea in } \\
\text { approximately } \\
1 \% \text { of patients }{ }^{35}\end{array}$ \\
\hline $\begin{array}{l}\text { Elinogrel } \\
40 \mathrm{mg}\end{array}$ & $\mathrm{R}$ & & Oral/intravenous & None required & 20 minutes & $\sim$ d day & No increase in bleeding \\
\hline SCH 530348 & $\mathrm{R}$ & $\begin{array}{l}\text { (>90\% to } \\
\text { TRAP) }\end{array}$ & Oral & None required & $\begin{array}{l}\text { With } \\
\text { LD: hours; } \\
\text { without } \\
\text { LD: days }\end{array}$ & Weeks & No increase in bleeding \\
\hline
\end{tabular}

Abbreviations: ADP, adenosine diphosphate; CYP, cytochrome P450; IRR, irreversible; LD, loading dose; R, reversible; TRAP, thrombin receptor antagonist peptide.

patients already receiving clopidogrel, including those with the highest platelet aggregation response.

On the basis of previous dose-confirmation trials, the Phase 3 PLATO (PLATelet inhibition and patient Outcomes) trial was conducted to compare ticagrelor and clopidogrel with respect to their efficacy in preventing cardiovascular events and safety. ${ }^{31}$ In this trial, 18,624 patients with ACS (both with and without ST-segment elevation), in addition to the aspirin therapy, received loading doses of ticagrelor $180 \mathrm{mg}$ or clopidogrel $300 \mathrm{mg}$ (with an additional $300 \mathrm{mg}$ clopidogrel at PCI) and then ticagrelor $90 \mathrm{mg}$ twice daily or clopidogrel $75 \mathrm{mg}$ once daily for 6-12 months. As compared to treatment with clopidogrel, ticagrelor was found to significantly reduce the rate of death from vascular causes, MI, or stroke (primary end point: $11.7 \%$ vs $9.8 \% ; P<0.001$ ), without an increase in the rate of overall major bleeding. ${ }^{31}$ These findings are noteworthy in that ticagrelor is the first investigational antiplatelet to demonstrate a reduction in cardiovascular death when compared with clopidogrel in patients with ACS. Ticagrelor reduced the risk of cardiovascular events early on, and this benefit over clopidogrel increased over time. Among the subset of patients who received a stent during the study, a 38\% RRR of definite stent thrombosis was achieved with ticagrelor $(1.0 \%$ vs $1.6 \%$;
$P=0.003) .{ }^{40}$ Patients weighing less than the median weight for their sex, those who were not on lipid-lowering drugs at randomization, and those from North America were found to attain fewer benefits from ticagrelor treatment. ${ }^{31}$ Although there was no increased risk of CABG-related bleeding, the PLATO investigators did find an increase in the rate of non-procedure-related bleeding (clopidogrel $3.8 \%$ vs ticagrelor $4.5 \% ; P=0.03$ ), including more instances of fatal intracranial bleeding but fewer instances of fatal bleeding of other types. ${ }^{31}$ The summation of major and minor bleeding events also showed an increase with ticagrelor when compared with clopidogrel (ticagrelor $16.1 \%$ vs clopidogrel $14.6 \%$; $P=0.008) .{ }^{40}$ In addition to the bleeding tendency, in line with the findings of Phase 2 trials, ticagrelor was associated with more ventricular pauses in the first week (ticagrelor $5.8 \%$ vs clopidogrel $3.6 \% ; P=0.01$ ), but not at day 30 , and with more reports of dyspnea (ticagrelor $13.8 \%$ vs clopidogrel $7.8 \%$; $P<0.001) .{ }^{31}$ The former occurred without clinical consequences for the patient, whereas the latter was responsible for 1 in 100 ticagrelor-treated patients stopping treatment. ${ }^{41}$ Thus, dyspnea was clinically limiting in around $1 \%$ of ticagrelor-treated patients. This rare but clinically meaningful and recurring finding awaits authoritative assessment and explanation. Given the large database of the PLATO trial, 
Table 2 Ticagrelor: results of clinical trials

\begin{tabular}{|c|c|c|c|c|}
\hline Phase & Clinical trial & Patients & Dosage & Results \\
\hline \multirow[t]{3}{*}{ Phase 2} & DISPERSE $^{36}$ & $\begin{array}{l}200 \text { patients } \\
\text { with atherosclerosis }\end{array}$ & $\begin{array}{l}\text { Randomization to ticagrelor } \\
\text { (doses of } 50,100 \text {, or } 200 \mathrm{mg} \\
\text { TD, or } 400 \mathrm{mg} \text { OD) or } \\
\text { clopidogrel ( } 75 \mathrm{mg} \text { OD), } \\
\text { on top of aspirin ( } 75-100 \mathrm{mg} \text { OD), } \\
\text { for } 28 \text { days }\end{array}$ & $\begin{array}{l}\text { Ticagrelor TD produced a more rapid } \\
\text { and greater IPA than clopidogrel } \\
(90 \% \text { vs } 60 \%)\end{array}$ \\
\hline & DISPERSE- $2^{37}$ & $\begin{array}{l}990 \text { patients } \\
\text { with non-ST-segment } \\
\text { elevation ACS }\end{array}$ & $\begin{array}{l}\text { Randomization to ticagrelor } \\
\text { ( } 90 \text { or } 180 \mathrm{mg} \text { TD) or } \\
\text { clopidogrel ( } 75 \mathrm{mg} \text { OD), } \\
\text { on top of aspirin } \\
\text { ( } 75 \text { and } 100 \mathrm{mg} \text { OD), } \\
\text { for up to } 12 \text { weeks }\end{array}$ & $\begin{array}{l}\text { No difference was observed in the total } \\
\text { bleeding rate between } 90-\mathrm{mg} \\
\text { ticagrelor-treated, I80-mg } \\
\text { ticagrelor-treated, and clopidogrel- } \\
\text { treated groups ( } 9.8 \%, 8.0 \% \text {, and } 8.1 \% \text {, } \\
\text { respectively) }\end{array}$ \\
\hline & ONSET/OFFSET ${ }^{38}$ & $\begin{array}{l}\text { I } 23 \text { patients } \\
\text { with stable CAD }\end{array}$ & $\begin{array}{l}\text { Randomization to ticagrelor } \\
\text { ( } 90 \mathrm{mg} \text { TD), clopidogrel } \\
\text { ( } 75 \mathrm{mg} \text { OD), or placebo, } \\
\text { on top of aspirin ( } 75-100 \mathrm{mg} \text { OD), } \\
\text { for } 6 \text { weeks }\end{array}$ & $\begin{array}{l}\text { Ticagrelor achieved more rapid and } \\
\text { greater platelet inhibition than high-LD } \\
\text { clopidogrel }>50 \% \text { IPA ( } 98 \% \text { vs } 31 \% \text {, } \\
P<0.000 \text { I) and }>70 \% \text { IPA ( } 90 \% \text { vs } \\
16 \%, P<0.000 \text { I) at } 2-h \text { post-LD; this } \\
\text { was sustained during the maintenance } \\
\text { phase and was faster in offset after } \\
\text { drug discontinuation }\end{array}$ \\
\hline Phase 3 & PLATO $^{31}$ & $\begin{array}{l}18,624 \text { patients } \\
\text { with ACS }\end{array}$ & $\begin{array}{l}\text { Randomization to LDs of } \\
\text { ticagrelor ( } 180 \mathrm{mg} \text { ) or } \\
\text { clopidogrel ( } 300 \mathrm{mg} \text {; with an } \\
\text { additional } 300 \mathrm{mg} \text { clopidogrel at } \\
\mathrm{PCl} \text { ), then ticagrelor ( } 90 \mathrm{mg} \mathrm{TD}) \\
\text { or clopidogrel ( } 75 \mathrm{mg} \text { OD), on } \\
\text { top of aspirin ( } 75-100 \mathrm{mg} \text { OD), } \\
\text { for } 6-12 \text { months }\end{array}$ & $\begin{array}{l}\text { Compared with clopidogrel treatment, } \\
\text { ticagrelor treatment was found to } \\
\text { significantly reduce the rate of death } \\
\text { from vascular causes, MI, or stroke } \\
\text { (primary end point: II.7\% vs } 9.8 \% \text {, } \\
P<0.00 \mathrm{I} \text { ), without an increase in } \\
\text { the rate of overall major bleeding }\end{array}$ \\
\hline
\end{tabular}

Abbreviations: ACS, acute coronary syndrome; CAD, coronary artery disease; IPA, inhibition of platelet aggregation; LD, loading dose; MI, myocardial infarction; OD, once daily; $\mathrm{PCI}$, percutaneous coronary intervention; $\mathrm{TD}$, twice daily.

analyses continue to be made of the findings. A subanalysis of patients with STEMI (PLATO STEMI) also showed that compared with clopidogrel treatment, ticagrelor treatment reduced cardiovascular events for up to a year $(11.0 \%$ vs $9.3 \% ; P=0.02)$, a difference driven mainly by a statistically significant reduction in MIs $(6.1 \%$ vs $4.7 \% ; P=0.01)$, without an increase in major bleeding. ${ }^{42}$

In the meantime, results of further Phase 2 trials of ticagrelor were released. The ONSET/OFFSET study $(n=123)$ was designed to assess the rates of onset and offset of the antiplatelet effects of ticagrelor versus clopidogrel taken for 6 weeks by patients with stable CAD receiving aspirin therapy. ${ }^{38}$ Using the same dosing scheme as that used in PLATO trial, it showed that ticagrelor achieved faster onset ( $41 \%$ IPA vs $8 \%$ at 30 minutes; $P<0.0001$ ), greater IPA, and faster offset in comparison with clopidogrel. The RESPOND trial, through a two-way crossover, investigated the antiplatelet effect of ticagrelor in 98 patients with stable CAD, which included both clopidogrel responders and clopidogrel nonresponders. ${ }^{43,44}$ The importance of this issue is reflected in reports estimating the frequency of clopidogrel nonresponders at about $10 \%$ and low responders at about $20 \% .{ }^{44}$ Among patients identified as clopidogrel responders, switching from clopidogrel to ticagrelor resulted in a mean IPA increase of 26\%, whereas switching from ticagrelor to clopidogrel resulted in a mean IPA decrease of $24 \% .{ }^{45}$ Thus, the RESPOND trial found that patients could be switched from ticagrelor treatment to clopidogrel treatment without the interruption of antiplatelet effect. It was concluded that clopidogrel nonresponders and responders exhibit superior platelet inhibition during ticagrelor therapy. However, the RESPOND trial findings also demonstrated that because of the variability of the clopidogrel response, identification of clopidogrel nonresponders is difficult. ${ }^{41}$ Finally, research has shown ticagrelor to produce platelet inhibition, regardless of the genotypic variations in the three genes that had been associated with the variability in platelet reactivity. ${ }^{39}$

All these trials underline the potential of ticagrelor to achieve a rapid and sustained antiplatelet effect, which could be reversed and could overcome nonresponsiveness and interpatient variability to clopidogrel, thus addressing the main limitations of clopidogrel therapy. ${ }^{3}$ Nonetheless, 
its adverse effects such as dyspnea and bradycardia, its relationship with patient weight, and the lack of its benefit in North American patients require further investigation before ticagrelor may advance further toward a place in antiplatelet therapy guidelines. ${ }^{31}$

\section{Other antiplatelet drugs in research and development and their clinical potential}

Cangrelor, another novel reversible $\mathrm{P}_{2} \mathrm{Y}_{12}$ antagonist, is a chemically modified version of ticagrelor, which can be administered parenterally. It acts rapidly, producing profound platelet inhibition within 15 minutes of initiating infusion when compared with the 1- to 2-hour time frame for prasugrel and ticagrelor. This intravenous (iv) adenosine triphosphate analog has a plasma half-life of 5-9 minutes and is highly reversible, so the platelet function returns to the baseline level of activation 20 minutes after the discontinuation of cangrelor. ${ }^{14,46,47}$ Because of such a rapid offset, cangrelor was foreseen as a drug for the catheterization laboratory; like GP IIb/IIIa antagonists, it has to be started right before a PCI procedure and stopped immediately after it, while other antiplatelets would provide long-term protection from then onward. ${ }^{46,48}$ Phase 2 safety trials did not note any deaths or serious events attributed to cangrelor. ${ }^{46,47}$ CHAMPION-PCI (A Clinical Trial Comparing Cangrelor to Clopidogrel in Subjects Who Require Percutaneous Coronary Intervention), a prospective Phase 3 trial of 9,000 patients with unstable angina, MI, or ACS awaiting PCI, aimed to compare the efficacy of cangrelor with that of clopidogrel in subjects requiring $\mathrm{PCI} .{ }^{49} \mathrm{On}$ the other hand, the CHAMPION PLATFORM (A Clinical Trial Comparing Treatment With Cangrelor [in Combination With Usual Care] to Usual Care, in Subjects Who Require Percutaneous Coronary Intervention), a trial on 6400 patients requiring PCI, planned to test the potential superiority of cangrelor (combined with usual care) over the placebo, as measured by a composite of all-cause mortality, MI, and ischemia-driven revascularization. ${ }^{50}$ Both studies have been terminated due to insufficient evidence of cangrelor's clinical efficacy. ${ }^{51}$

Although no Phase 3 data are available, another Phase 2 study is in progress, with the purpose of demonstrating that patients receiving cangrelor infusion before $\mathrm{CABG}$ have an acceptable safety profile and can undergo surgery without excessive perioperative bleeding. This maintenance of platelet inihiBition with cangRelor after dIscontinuation of thienopyriDines in patients undergoing surGEry (BRIDGE) trial plans to follow up 220 patients undergoing nonemergent
$\mathrm{CABG}$, who had already received a thienopyridine antiplatelet drug, and foresees completion in July 2010.52

Elinogrel (also known as PRT060128), the next addition to the reversible, direct-acting nonthienopyridine $\mathrm{P} 2 \mathrm{Y}_{12}$ receptor antagonists, is unique in that it can be administered both orally and intravenously. ${ }^{53}$ This allows for an immediate and reversible effect of high-level platelet inhibition, preferable in acute conditions, and an easy transition to reversible platelet inhibition in the chronic setting. ${ }^{54}$ Its simplified administration covers the full spectrum of care, from acute onset to chronic care, and its reversibility allows for surgery without significant delay. Thus far, elinogrel has undergone Phase 2A ERASE MI (Early Rapid ReversAl of platelet thromboSis with intravenous Elinogrel before PCI to optimize reperfusion in acute Myocardial Infarction) pilot trial. ${ }^{55}$ In this safety and efficacy dose-escalation trial, 70 patients with STEMI undergoing primary PCI were randomized to an iv bolus of placebo versus elinogrel (at doses of $10,20,40$, and $60 \mathrm{mg}$ ), in addition to standard treatment, prior to angiography. There appeared to be no difference between the placebo and elinogrel (at doses of 10, 20, 40, and $60 \mathrm{mg}$ ) with respect to the incidence of the infrequent bleeding events. Neither were there any differences in serious adverse events, laboratory values, and corrected thrombolysis in MI (TIMI) frame count, nor was any ST resolution between elinogrel and placebo. ${ }^{56}$ Although the dose-confirmation phase was not started, as the trial was prematurely terminated for administrative reasons, the ERASE MI findings provide preliminary support for the use of elinogrel as an adjunctive therapy in primary PCI for STEMI. Meanwhile, the results of elinogrel's Phase 2b INNOVATE-PCI (A randomized, double-blind, active-controlled trial to evaluate intravenous and oral PRT060128, a selective and reversible P2Y12 inhibitor, vs clopidogrel, as a novel antiplatelet therapy in patients undergoing nonurgent $\mathrm{PCI}$ ) are awaited. In this trial, 800 patients, who were randomized to the clopidogrel control or to one of three experimental regimens of elinogrel (80-mg bolus administered intravenously prior to PCI, followed by twice-daily oral dosing of 50,100, or $150 \mathrm{mg}$ ), are being studied prior to nonurgent PCI and in the 60-day chronic treatment phase. ${ }^{57}$ INNOVATE-PCI is designed not to examine a prespecified endpoint, but rather to explore a number of analyses to understand the clinical efficacy, biological activity, tolerability, and safety of elinogrel.

Two more investigational nonthienopyridine $\mathrm{P} 2 \mathrm{Y}_{12}$ antagonists, BX 667 and its active metabolite BX 048, are in the early stages of clinical development. Thus far, they have undergone animal trials, performed on rat and dog models, 
and pharmacodynamic and pharmacokinetic studies. ${ }^{58,59}$ They are hoped to be useful in safely decreasing cardiovascular events in patients undergoing PCI.

Besides the great variety of new ADP receptor antagonists, a new class of antiplatelet agents targeting the potent thrombin-induced activation of platelets is emerging. The first member of these thrombin receptor antagonists (TRAs) SCH 530348 and the second member E5555 antagonize the platelet PAR1. This receptor found in platelets and smooth muscle cells possesses a high affinity to thrombin and via coupling to $\mathrm{G}_{\mathrm{p}} / \mathrm{G}_{\mathrm{i}}$ proteins, mediates the activation of these cells by thrombin. ${ }^{11}$ The safety and efficacy of SCH 530348 have already been tested in various Phase 2 trials, including the TRA-PCI study, and two Phase 3 trials are presently being conducted. ${ }^{60}$ The TRA $2\left(^{\circ}\right)$ P-TIMI 50 trial (Thrombin Receptor Antagonist in Secondary Prevention of Atherothrombotic Ischemic Events) on approximately 19,500 patients with atherosclerotic disease (prior MI or stroke or with existing peripheral arterial disease), in the course of at least 1-year follow-up, compares the safety and efficacy of SCH 530348 against the existing standard of care (aspirin and clopidogrel) in preventing MI, stroke, and urgent coronary revascularization and in assessing its bleeding risk. ${ }^{61}$ On the other hand, the TRA-CER (Thrombin Receptor Antagonist for Clinical Event Reduction in Acute Coronary Syndrome) study is designed to compare the efficacy of a combination of SCH 530348 and the existing standard of care (eg, aspirin and clopidogrel) with that of the existing standard of care alone in preventing MI and stroke in patients with ACS. ${ }^{62}$ By following up approximately 10,000 patients with non-STEMI for a minimum of 1 year, the study will also assess the bleeding risk of both treatment variants (ie, a combination of SCH 530348 and the existing standard of care, and the existing standard of care alone). The results of these large-scale trials, planned to be completed in September 2010 and July 2011, respectively, are eagerly awaited. The other member of the TRA group, E5555, is currently being evaluated in two Phase 2 trials, LANCELOT (Lessons from Antagonizing the Cellular Effects Of Thrombin) trials 201 and 202. ${ }^{63,64}$ In each trial, approximately 600 patients with CAD will be followed up in order to assess E5555's safety and efficacy in inhibiting platelet aggregation and endovascular inflammatory processes and to measure the incidence of major adverse cardiovascular events.

There are also new up-and-coming drugs interfering with the thromboxane pathway, upon which aspirin acts. NCX 4016 (nitroaspirin) is a nitric oxide-releasing aspirin that combines all the benefits of aspirin with those of nitric oxide. ${ }^{65} \mathrm{NCX} 4016$, with its antithrombotic, antiatherogenic, and vasodilatory properties, is known to be strongly cardioprotective. Also being evaluated is S18886 (terutroban), a TXA 2 receptor inhibitor, currently undergoing the PERFORM (Prevention of Cerebrovascular and Cardiovascular Events of Ischemic Origin with Terutroban in Patients with a History of Ischemic Stroke or Transient Ischemic Attack) study in patients with recent stroke or transient ischemic attack. ${ }^{12,66}$ This Phase 2 trial is designed to compare this specific TP receptor antagonist with aspirin in reducing the incidence of cerebrovascular and cardiovascular events. ${ }^{67}$ Terutroban may be of particular interest because studies in a murine model have shown the inhibition of the $\mathrm{TXA}_{2}$ receptor to decrease atherosclerosis progression. ${ }^{68}$ Moreover, novel antithrombotic compounds discovered inhibit thrombin while antagonizing GP IIb/IIIa. The future of such dual-function pharmaceuticals in CVDs remains to be seen. The same is true for PR-15, the investigational platelet GP VI adhesion antagonist, and the drugs targeting platelet endothelial aggregation receptor $1 .{ }^{69,70}$

\section{Conclusions and future research}

Given the pathologic process of intraarterial platelet activation underlying CVDs, it is clear that antiplatelet therapeutic options are needed for treating CVDs and preventing their complications. Significant progress has already been made in the field of antiplatelet therapy, as it aims to inhibit platelet aggregation and acute thrombus formation, while preventing intolerable bleeding. There exists a growing spectrum of drugs modifying these pathologic processes, which continues to expand in the hopes of overcoming the limitations of current standard treatment. Novel platelet-inhibiting drugs act through diverse mechanisms, mostly interfering with ADP-induced platelet aggregation, but also targeting the TXA $_{2}$ pathway and thrombin-induced signaling. ${ }^{11-13}$ In contrast to the available GP IIb/IIIa antagonists, which block the final common pathway of platelet aggregation, the possibility emerges of disrupting initial mechanisms of adhesion by targeting GP IV, a key receptor for collagen ${ }^{69}$ As combination regimens are often required to achieve sufficient platelet inhibition, new approaches to old mechanisms are explored, such as the combination of nitric oxide and aspirin in the investigational agent NCX 4016. ${ }^{65}$

As our understanding of the complex molecular and genetic bases of atherothrombotic disease expands, modern medicine moves toward more individualized patient treatment. The growing stock of antiplatelet drugs at our disposal can help us treat the full spectrum of and various stages 
in atherothrombotic manifestations of atherosclerosis while catering to the needs and risk factors of specific patients. This is slowly becoming a reality, for example, prasugrel is especially useful in patients with high risk of ischemic events as in those with diabetes mellitus. ${ }^{19,28,29}$ Ticagrelor is possibly a useful agent before $\mathrm{CABG}$, as its more potent platelet inhibition did not increase CABG-related bleeding, although its side effects such as dyspnea and ventricular pauses could additionally limit its patient base. ${ }^{31}$ On the other hand, both prasugrel and ticagrelor seem less liable to decreased patient response because of genetic polymorphism of receptors and enzymes; thus, these agents potentially provide platelet inhibition in patients who are clopidogrel nonresponders. ${ }^{22,38,39}$ Elinogrel, even though it has not entered Phase 3 trials, is encouraging because of its simplified administration scheme, allowing for a smooth transition from acute to chronic treatment.

Progress with respect to the potency of platelet inhibition has also brought increased bleeding tendency. To shift the balance from causing excess bleeding toward preventing vascular occlusion, dose adjustments are necessary in low-weight patients for drugs such as prasugrel and ticagrelor. ${ }^{29,31}$ As age is another factor found to increase bleeding, elderly patients still await a registered drug to address their needs. In contrast to the studies on clopidogrel and prasugrel, ticagrelor, besides its stronger platelet inhibition, did not increase the risk of major bleeding; thus, it may become an antiplatelet option for older patients, although it may not be possible for those with respiratory problems or symptomatic bradycardia. ${ }^{30,31,34}$ Also, with regard to bleeding, the group of thrombin receptor inhibitors is particularly promising, as it is hypothesized that the pathway they block may play a role only in pathologic thrombosis, leaving physiologic hemostasis intact. Such an advantage with respect to bleeding risk is also evidenced by animal studies, showing a decrease in the progression of atherosclerosis. ${ }^{11,68}$

Dyspnea, another clinically relevant adverse effect, was found to occur in up to $5 \%, 8 \%, 14 \%$, and $1 \%$ of patients receiving prasugrel, clopidogrel, ticagrelor, and cangrelor, respectively. ${ }^{30,31,34,35}$ An analysis by Serebruany et $\mathrm{al}^{71}$ considered the pathophysiology of the respiratory distress and platelet inhibition. The authors found dyspnea to be a very rare complication, mostly caused by underlying diseases - cardiac, respiratory, or allergic - and concomitant medications (high-dose angiotensin-converting enzyme inhibitors) rather than by the antiplatelet therapy itself. It was suggested that especially reversible agents (like ticagrelor) could lead to the development of mild, asymptomatic thrombotic thrombocytopenic purpura, fluid retention, and dyspnea. Another proposed hypothesis is that certain antiplatelets may be metabolized to adenosine (ticagrelor's molecular structure has components almost identical to those of adenosine), which is an established bronchoprovocator. Although the true reason for the statistically significant increase in dyspnea - particularly with ticagrelor - remains to be uncovered, it is clear that further studies should follow up this finding to assess its clinical significance in the long-term care of patients with atherothrombotic disease. ${ }^{71}$

In summary, the abundant novel antiplatelet agents, with their higher potencies, higher platelet specificities, various drug formulations, possible reversibility, less variability in patient response, more rapid onsets and offsets of action, and short time to peak, along with their attempts for better safety, hold high potential. Some are in advanced stages of development with assuring outcomes, and further clinical evaluation is needed to determine which of them will find a place within standard antiplatelet therapy.

\section{Disclosures}

The authors report no conflicts of interest. The authors alone are responsible for the content and writing of this paper.

\section{References}

1. Jennings LK. Role of platelets in atherothrombosis. Am J Cardiol. 2009;103:4-10.

2. Awtry EA, Loscalzo J. Cardiovascular drugs - aspirin. Circulation. 2000;101:1206-1218.

3. Patrono C, Coller B, FitzGerald GA, Hirsh J, Roth G. Platelet-active drugs: the relationships among dose, effectiveness, and side effects. The Seventh ACCP Conference on Antithrombotic and Thrombolytic Therapy. Chest. 2004;126 Suppl 3:S234-S264.

4. Antithrombotic Trialists' Collaboration. Collaborative meta-analysis of randomised trials of antiplatelet therapy for prevention of death, myocardial infarction, and stroke in high risk patients. $B M J$. 2002;324:71-86.

5. Yusuf S, Zhao F, Mehta SR, et al. Effects of clopidogrel in addition to aspirin in patients with acute coronary syndromes without ST-segment elevation. N Eng J Med. 2001;345:494-502.

6. Snoep JD, Hovens MM, Eikenboom JC, van der Bom JG, Jukema JW, Huisman MV. Clopidogrel nonresponsiveness in patients undergoing percutaneous coronary intervention with stenting: a systematic review and meta-analysis. Am Heart J. 2007;154:221-231.

7. Gori AM, Marcucci R, Migliorini A. Incidence and clinical impact of dual nonresponsiveness to aspirin and clopidogrel in patients with drug-eluting stents. J Am Coll Cardiol. 2008;52:734-739.

8. Kamath S, Blannand AD, Lip GYH. Platelet activation: assessment and quantification. Eur Heart J. 2001;22:1561-1571.

9. Shankar H, Kunapuli SP. Is the P2Y1 receptor a better target for antithrombotic drugs? Drug Discov Today. 2005;2:285-290.

10. Quinton TM, Murugappan S, Kim S, Jin J, Kunapuli SP. Different $\mathrm{G}$ protein-coupled signaling pathways are involved in alpha granule release from human platelets. J Thromb Haemost. 2004;2:978-984.

11. Hamilton J. Protease-activated receptors as targets for antiplatelet therapy. Blood Rev. 2009;23:61-65.

12. Kakkos SK, Nicolaides AN. S-18886 Servier. Curr Opin Investig Drugs. 2002;3:1324-1327. 
13. Michelson AD. P2Y12 antagonism: promises and challenges. Arterioscler Thromb Vasc Biol. 2008;28:33-38.

14. Sabatine MS. Novel antiplatelet strategies in acute coronary syndromes. Cleve Clin J Med. 2009;76:8-14.

15. Mangin P, Ohlmann P, Eckly A, Cazenave JP, Lanza F, Gachet C. The P2Y1 receptor plays an essential role in the platelet shape change induced by collagen when TxA2 formation is prevented. $J$ Thromb Haemost. 2004;2:969-977.

16. Storey RF. Biology and pharmacology of the platelet P2Y12 receptor. Curr Pharm Des. 2006;12:1255-1259.

17. Jin J, Quinton T, Zhang J, Rittenhouse SE, Kunapuli SP. Adenosine diphosphate (ADP)-induced thromboxane $\mathrm{A}(2)$ generation in human platelets requires coordinated signaling through integrin alpha(IIb) beta(3) and ADP receptors. Blood. 2002;99:193-198.

18. Schomig A. Ticagrelor - is there need for a new player in the antiplatelettherapy field? N Engl J Med. 2009;11:1108-1111.

19. Kushner FG, Hand M, Smith SC Jr, et al. 2009 focused updates: ACC/ AHA guidelines for the management of patients with ST-elevation myocardial infarction and ACC/AHA/SCAI guidelines on percutaneous coronary intervention. J Am Coll Cardiol [serial on the Internet]. 2009 [cited 2009 Nov 18];54:2205-2241. http://content.onlinejacc.org/cgi/ content/full/j.jacc.2009.10.015. Accessed 2009 December 16.

20. National Institute for Health and Clinical Excellence. Prasugrel for the treatment of acute coronary syndromes with percutaneous coronary intervention [cited 2009 Oct]. http://www.nice.org.uk/TA182. Accessed 2009 December 16.

21. Wallentin L, Varenhorst C, James S, et al. Prasugrel achieves greater and faster P2Y12 receptor mediated platelet inhibition than clopidogrel due to more efficient generation of its active metabolite in aspirin-treated patients with coronary artery disease. Eur Heart J. 2008;29:21-30.

22. Brandt JT, Close SL, Iturria SJ, et al. Common polymorphisms of CYP2C19 and CYP2C9 affect the pharmacokinetic and pharmacodynamic response to clopidogrel but not prasugrel. JThromb Haemost. 2007;5:2429-2436.

23. Varenhorst C, James S, Erlinge D, et al. Genetic variation of CYP2C19 affects both pharmacokinetic and pharmacodynamic responses to clopidogrel but not prasugrel in aspirin-treated patients with coronary artery disease. Eur Heart J. 2009;30:1744-1752.

24. Mega JL, Close SL, Wiviott SD, et al. Cytochrome P450 genetic polymorphisms and the response to prasugrel: relationship to pharmacokinetic, pharmacodynamic, and clinical outcomes. Circulation. 2009;119:2553-2560.

25. Small DS, Farid NA, Payne CD, et al. Effects of the proton pump inhibitor lansoprazole on the pharmacokinetics and pharmacodynamics of prasugrel and clopidogrel. J Clin Pharmacol. 2008;48:475-484.

26. Brandt JT, Payne CD, Wiviott SD, et al. A comparison of prasugrel and clopidogrel loading doses on platelet function: magnitude of platelet inhibition is related to active metabolite formation. Am Heart J. 2007;153:9-16.

27. Niitsu Y, Jakubowski JA, Sugidachi A, Asai F. Pharmacology of CS-747 (prasugrel, LY640315), a novel, potent antiplatelet agent with in vivo P2Y12 receptor antagonist activity. Semin Thromb Hemost. 2005;31:184-194.

28. Wiviott SD, Braunwald E, Angiolillo DJ, et al. Greater clinical benefit of more intensive oral antiplatelet therapy with prasugrel in patients with diabetes mellitus in the trial to assess improvement in therapeutic outcomes by optimizing platelet inhibition with prasugrel - thrombolysis in myocardial infarction 38. Circulation. 2008;118:1626-1636.

29. Wiviott SD, Braunwald E, McCabe $\mathrm{CH}$, et al. Prasugrel versus clopidogrel in patients with acute coronary syndromes. $N$ Engl J Med. 2007;357:2001-2015.

30. Antman EM, Wiviott SD, Murphy SA, et al. Early and late benefits of prasugrel in patients with acute coronary syndromes undergoing percutaneous coronary intervention: a TRITON-TIMI 38 (TRial to Assess Improvement in Therapeutic Outcomes by Optimizing Platelet InhibitioN with Prasugrel - Thrombolysis In Myocardial Infarction) analysis. J Am Coll Cardiol. 2008;51:2028-2033.
31. Wallentin L, Becker RC, Budaj A, et al. Ticagrelor versus clopidogrel in patients with acute coronary syndromes. $N$ Engl J Med. 2009;361: $1045-1057$.

32. Tantry US, Bliden KP, Gurbel PA. AZD6140. Expert Opin Investig Drugs. 2007;16:225-229.

33. Peters GR, Butler KA, Winter HR. Multiple-dose pharmacokinetics (PK) and pharmacodynamics (PD) of the reversible, orally active ADP receptor antagonist AZD6140 [abstract]. Eur Heart J. 2006;27 Suppl 1:S758.

34. CAPRIE Steering Committee. A randomized, blinded, trial of clopidogrel versus aspirin in patients at risk of ischaemic events (CAPRIE). Lancet. 1996;348:1329-1339.

35. Harrington RA, Stone GW, McNulty S, et al. Platelet inhibition with cangrelor in patients undergoing PCI. N Engl J Med. 2009;361: 2318-2329.

36. Husted S, Emanuelsson H, Heptinstall S, Sandset PM, Wickens M, Peters G. Pharmacodynamics, pharmacokinetics, and safety of the oral reversible P2Y12 antagonist AZD6140 with aspirin in patients with atherosclerosis: a double-blind comparison to clopidogrel with aspirin. Eur Heart J. 2006;27:1038-1047.

37. Cannon CP, Husted S, Harrington RA, et al. Safety, tolerability, and initial efficacy of AZD6140, the first reversible oral adenosine diphosphate receptor antagonist, compared with clopidogrel, in patients with non-ST-segment elevation acute coronary syndrome: primary results of the DISPERSE-2 trial. J Am Coll Cardiol. 2007;50:1844-1851.

38. Gurbel PA, Bliden KP, Butler K, et al. Randomized double-blind assessment of the ONSET and OFFSET of the antiplatelet effects of ticagrelor versus clopidogrel in patients with stable coronary artery disease: The ONSET/OFFSET study. Circulation. 2009;120:2511-2522.

39. Storey RF, Thornton SM, Lawrance R, et al. Ticagrelor yields consistent dose-dependent inhibition of ADP-induced platelet aggregation in patients with atherosclerotic disease regardless of genotypic variations in P2RY12, P2RY1, and ITGB3. Platelets. 2009;20:341-348.

40. AstraZeneca press release. Results from two phase II Trials add to understanding of Brilinta (ticagrelor) and how it works in the body [cited 2009 Nov 18]. http://www.astrazeneca.com/media/ latest-press-releases/2009/Brilinta_Phase_II_AHA?itemId = 7499699. Accessed 2009 December 16.

41. AstraZeneca press release. Phase III head to head trial showed ticagrelor reduced cardiovascular death and heart attacks over clopidogrel in acute coronary syndromes patients [cited 2009 Aug 30]. http://www. astrazeneca.com/media/latest-press-releases/2009/plato-esc?itemId = 6868332. Accessed 2009 December 16.

42. AstraZeneca press release. BRILINTA demonstrated greater efficacy over clopidogrel in the most urgent clinical setting: patients with ST-segment elevation myocardial infarction and planned percutaneous coronary intervention (PCI) [cited 2009 Nov 16]. http://www.astrazeneca.com/media/latest-press releases/2009/PLATO_STEMI?itemId = 7476684. Accessed 2009 December 16.

43. Clinical Trials.gov [homepage on the Internet]. A study of the antiplatelet effects comparing AZD6140 with clopidogrel responder and non-responders (RESPOND) [updated 2009 Apr 23]. http://clinicaltrials.gov/ct2/show/ NCT00642811. Accessed 2009 December 16.

44. Müller I, Besta F, Schulz C, Massberg S, Schönig A, Gawaz M. Prevalence of clopidogrel non-responders among patients with stable angina pectoris scheduled for elective coronary stent placement. Thromb Haemost. 2003;89:783-787.

45. Gurbel PA, Bliden KP, Antonino M, et al. Abstract 5901: the effect of ticagrelor in stable coronary artery disease patients nonresponsive to clopidogrel: the RESPOND study [abstract]. Circulation. 2009;120 Suppl:S1173.

46. Greenbaum AB, Grines CL, Bittl JA, et al. Initial experience with an intravenous $\mathrm{P} 2 \mathrm{Y} 12$ platelet receptor antagonist in patients undergoing percutaneous coronary intervention: results from a 2-part, phase II, multicenter, randomized, placebo- and active-controlled trial. $\mathrm{Am}$ Heart J. 2006;151:689.e1-689.e10. 
47. Storey R, Oldroyd K, Wilcox R. Open multicentre study of the P2T receptor antagonist AR-C69931MX assessing safety, tolerability and activity in patients with acute coronary syndromes. Thromb Haemost. 2001;85:401-407.

48. Fugate SE, Cudd LA. Cangrelor for treatment of coronary thrombosis. Ann Pharmacother. 2006;40:925-930.

49. Clinical Trials.gov [homepage on the Internet]. A clinical trial to demonstrate the efficacy of cangrelor (PCI) [updated 2009 May 18] http://clinicaltrials.gov/ct2/show/NCT00305162. Accessed 2009 December 16.

50. Clinical Trials.gov [homepage on the Internet]. Cangrelor versus standard therapy to achieve optimal management of platelet inhibition (PLATFORM) [updated 2009 May 18]. http://clinicaltrials.gov/ct2/ show/NCT00385138. Accessed 2009 December 16.

51. The Medicines Company press release. The medicines company discontinues Phase 3 CHAMPION clinical trial program of cangrelor [cited 2009 May 13]. http://ir.themedicinescompany.com/phoenix. zhtml? $\mathrm{c}=122204 \& \mathrm{p}=$ irol-newsArticle \&ID=1287788\&highlight . Accessed 2009 December 16.

52. Clinical Trials.gov [homepage on the Internet]. Maintenance of platelet inhibition with cangrelor (BRIDGE) [updated 2009 Dec 9]. http://clinicaltrials.gov/ct2/show/NCT00767507. Accessed 2009 December 16.

53. Gretler DD, Conley PB, Andre P, et al. "First in human" experience with PRT060128, a new direct-acting, reversible, P2Y12 inhibitor for IV and oral use [abstract]. J Am Coll Cardiol. 2007;9 Suppl 2:326.

54. Lieu HD, Conley PB, Andre P, et al. Initial intravenous experience with PRT060128 (PRT128), an orally-available, direct-acting, and reversible P2Y12 inhibitor [abstract]. J Thromb Haemost. 2007;5 Suppl 2:P-T-292.

55. Clinical Trials.gov [homepage on the Internet]. Safety and efficacy study of adjunctive antiplatelet therapy prior to primary PCI in patients with STEMI (ERASE-MI) [updated $2008 \mathrm{Jul} 22$ ]. http://clinicaltrials.gov/ ct2/show/NCT00546260. Accessed 2009 December 16.

56. Berger JS, Roe MT, Gibson CM, et al. Safety and feasibility of adjunctive antiplatelet therapy with intravenous elinogrel, a direct-acting and reversible P2Y12 ADP-receptor antagonist, before primary percutaneous intervention in patients with ST-elevation myocardial infarction: the early rapid reversal of platelet thrombosis with intravenous elinogrel before PCI to optimize reperfusion in acute myocardial infarction (ERASE MI) pilot trial. Am Heart J. 2009;158(6):998.e1-1004.e1.

57. Clinical Trials.gov [homepage on the Internet]. A Phase 2 safety and efficacy study of PRT060128, a novel intravenous and oral P2Y12 inhibitor, in non-urgent PCI (INNOVATE-PCI) [updated 2009 Mar 29]. http://clinicaltrials.gov/ct2/show/NCT00751231. Accessed 2009 December 16.

58. Wang Y, Vincelette J, da Cunha V, et al. A novel P2Y(12) adenosine diphosphate receptor antagonist that inhibits platelet aggregation and thrombus formation in rat and dog models. Thromb Haemost. 2007;97(5):847-855

59. Post, JM, Alexander S, Wang YX, et al. Novel P2Y12 adenosine diphosphate receptor antagonists for inhibition of platelet aggregation (II): pharmacodynamic and pharmacokinetic characterization. Thromb Res. 2008;122:533-540.
60. Becker RC, Moliterno DJ, Jennings LK, et al. Safety and tolerability of SCH 530348 in patients undergoing non-urgent percutaneous coronary intervention: a randomised, double-blind, placebo-controlled phase II study. Lancet. 2009;373:919-928.

61. Morrow DA, Scirica BM, Fox KA, et al; TRA $2^{\circ}$ P-TIMI 50 Investigators. Evaluation of a novel antiplatelet agent for secondary prevention in patients with a history of atherosclerotic disease: design and rationale for the thrombin-receptor antagonist in secondary prevention of atherothrombotic ischemic events (TRA 2 degrees P)-TIMI 50 trial. Am Heart J. 2009;158:335-341.

62. Clinical Trials.gov [homepage on the Internet]. Trial to assess the effects of SCH 530348 in preventing heart attack and stroke in patients with acute coronary syndrome (TRA-CER) [updated 2009 Nov 23]. http://clinicaltrials.gov/ct2/show/NCT00527943. Accessed 2009 December 16.

63. Clinical Trials.gov [homepage on the Internet]. Safety and tolerability of E5555 and its effects on markers of intravascular inflammation in subjects with coronary artery disease [updated 2009 Sep 1]. http://clinicaltrials.gov/ct2/show/NCT00312052. Accessed 2009 December 16.

64. Clinical Trials.gov [homepage on the Internet]. Safety and tolerability of E5555 and its effects on markers of intravascular inflammation in subjects with acute coronary syndrome [updated $2009 \mathrm{Sep} 2$ ]. http://clinicaltrials. gov/ct2/show/NCT00548587. Accessed 2009 December 16.

65. Napoli C, Aldini G, Wallace JL, et al. Efficacy and age-related effects of nitric oxide-releasing aspirin on experimental restenosis. Proc Natl Acad Sci U S A. 2002;99:1689-1694.

66. Bousser MG, Amarenco P, Chamorro A, et al; for PERFORM Study Investigators. Rationale and design of a randomized, double-blind, parallel-group study of terutroban $30 \mathrm{mg} /$ day versus aspirin $100 \mathrm{mg} /$ day in stroke patients: the prevention of cerebrovascular and cardiovascular events of ischemic origin with terutroban in patients with a history of ischemic stroke or transient ischemic attack (PERFORM) study. Cerebrovasc Dis. 2009;27:509-518.

67. Chamorro A. TP receptor antagonism: a new concept in atherothrombosis and stroke prevention. Cerebrovasc Dis. 2009;27:20-27.

68. Cayatte AJ, Du Y, Oliver-Krasinski J, Lavielle G, Verbeuren TJ, Cohen RA. The thromboxane receptor antagonist S18886 but not aspirin inhibits atherogenesis in apo E-deficient mice: evidence that eicosanoids other than thromboxane contribute to atherosclerosis. Arterioscler Thromb Vasc Biol. 2000;20:1724-1728.

69. Shalito I, Kopyleva O, Serebruany V. Novel antiplatelet agents in development: prasugrel, ticagrelor, and cangrelor and beyond. $\mathrm{Am} \mathrm{J}$ Ther. 2009;16:451-458.

70. Nanda N, Bao M, Lin H, et al. Platelet endothelial aggregation receptor 1 (PEAR1), a novel epidermal growth factor repeat-containing transmembrane receptor, participates in platelet contact-induced activation. J Biol Chem. 2005;280:24680-24689.

71. Serebruany VL, Stebbing J, Atar D. Dyspnoea after antiplatelet agents: the AZD6140 controversy. Int J Clin Pract. 2007;61:529-533.
Vascular Health and Risk Management

\section{Publish your work in this journal}

Vascular Health and Risk Management is an international, peerreviewed journal of therapeutics and risk management, focusing on concise rapid reporting of clinical studies on the processes involved in the maintenance of vascular health; the monitoring, prevention and treatment of vascular disease and its sequelae; and the involvement of

\section{Dovepress}

metabolic disorders, particularly diabetes. This journal is indexed on PubMed Central and MedLine. The manuscript management system is completely online and includes a very quick and fair peer-review system, which is all easy to use. Visit http://www.dovepress.com/ testimonials.php to read real quotes from published authors. 